\title{
An Example of Failure of an Office Building in Upper Silesia
}

\author{
Kazimierz Konieczny ${ }^{1,}$, and Leszek Słowik ${ }^{1}$ \\ ${ }^{1}$ Building Research Institute, ul. Filtrowa 1, 00-611 Warsaw, Poland
}

\begin{abstract}
The paper describes an example of a failure of an office building in Upper Silesia, Poland. Following a technical description of the building, the authors describe the damage to the building structure and damage development. The causes of damage of the building structure are assessed and discussed. The main cause is a long-term failure of the water supply system that resulted in deterioration in the foundation subsoil. The investigations also showed previously unidentified subsoil deformation left after old mining exploitation. The paper concludes with the discussion of the ongoing restoration of the technical efficiency of the building.
\end{abstract}

\section{Introduction}

The paper concerns an office building located in one of the cities in Upper Silesia, which after more than 50 years of faultless operation suffered damage as a result of random events and the lack of the complete knowledge about the geological conditions in the design preparation phase.

\section{Technical description of the building}

The building, designed in 1963, has two aboveground levels without a basement. The building whose body has a simple, rectangular shape in projection consists of three segments separated with movement joints and differing from each other, both in terms of their function and structural solutions.

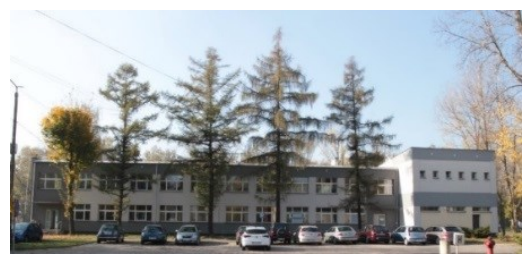

Fig. 1. General view of the administrative and office building.

\footnotetext{
*Corresponding author: k.konieczny@itb.pl, 1.slowik@itb.pl
} 
The foundations of the building, that have a form of mutually connected strips, were to transfer vertical loads from the structure to the ground and secure the building against the influence of category IIa discontinuous mining deformation of the land surface. The strips were placed on a $30 \mathrm{~cm}$ thick sand bedding layer compacted in layers and on a $10 \mathrm{~cm}$ thick layer of lean concrete. According to the original geological survey, the area on which the building was located was covered with a layer of topsoil and tip embankment (slag, blastfurnace sinter) of varying vertical thickness. Under the topsoil or below the embankment there occur layers of silt and sandy clay or clayey sand. Below these layers a weathered sandstone is present at various depths.

The groundwater table occurred below the foundation level.

The load-carrying structure of the office building consists of two longitudinal internal hall walls, $38 \mathrm{~cm}$ thick, made of solid ceramic brick (class 100). The $38 \mathrm{~cm}$ thick load-bearing external walls were made of lime-and-sand bricks. DZ-3 type ceilings are connected circumferentially with the load-bearing walls.

The roof is covered with hollow core roof plates laid on openwork walls, and above the conference room on the first floor, the plates were rested on steel trusses with a span of $9.0 \mathrm{~m}$. Projection of the ground floor of the facility is presented in Fig. 2.

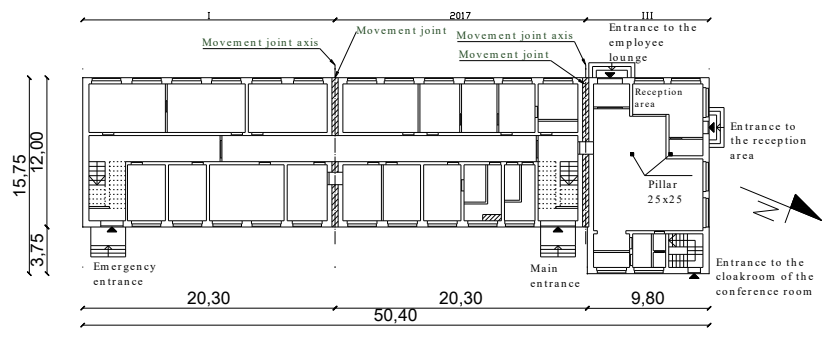

Fig. 2. Ground floor projection of the building.

In 2016, the external walls of the building were insulated with a $10 \mathrm{~cm}$ layer of foamed polystyrene using the ETICS system.

\section{Damage to the building structure}

During the first days of August 2018, in some of rooms on the ground floor in the middle and the extreme north segment (Fig. 1), damage to the structure of the walls, window and door lintels and concrete floors was observed. The damage consisted of:

- heavy cracking of internal longitudinal load-bearing walls, walls near movement joints and partition walls; the aperture of these cracks was up to ca. $15 \mathrm{~mm}$ (on the ground floor of the building) and ca. $5 \mathrm{~mm}$ in part of the first floor rooms.

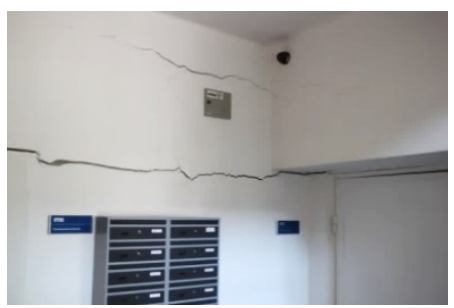

Fig. 3. Cracking in the longitudinal load-bearing wall on the ground floor of the building, passing onto the transversal wall located near the movement joint. 


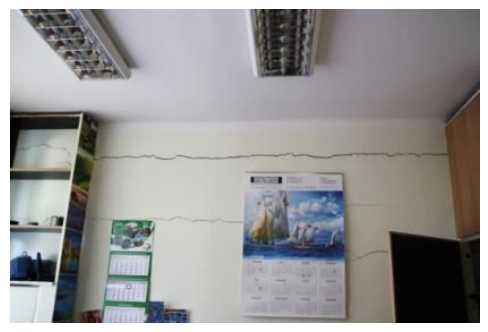

Fig. 4. Cracking of the transversal wall located near the movement joint on the ground floor of the building.

- cracking of the internal longitudinal load-bearing walls, walls near movement joints and partition walls and backs of window lintels with an aperture of up to ca. $5 \mathrm{~mm}$ on the first floor of the building,

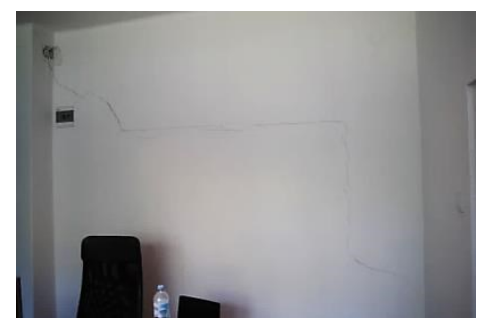

Fig. 5. Cracking of the load-bearing longitudinal wall of the first floor.

- cracking of the western external wall with an aperture of up to ca. $1.0 \mathrm{~cm}$, visible outside and inside office rooms,

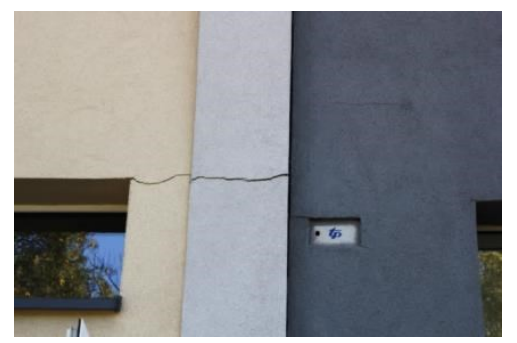

Fig. 6. Cracking of the thermal insulation layer of the external wall in the zone near the movement joint between the northern and central segments.

- local deformation (cracking and tilting to ca. $18 \%$.) of concrete floors in office rooms and the hallway of the ground floor of the building.

The location of the damage is shown in Figure 7. 


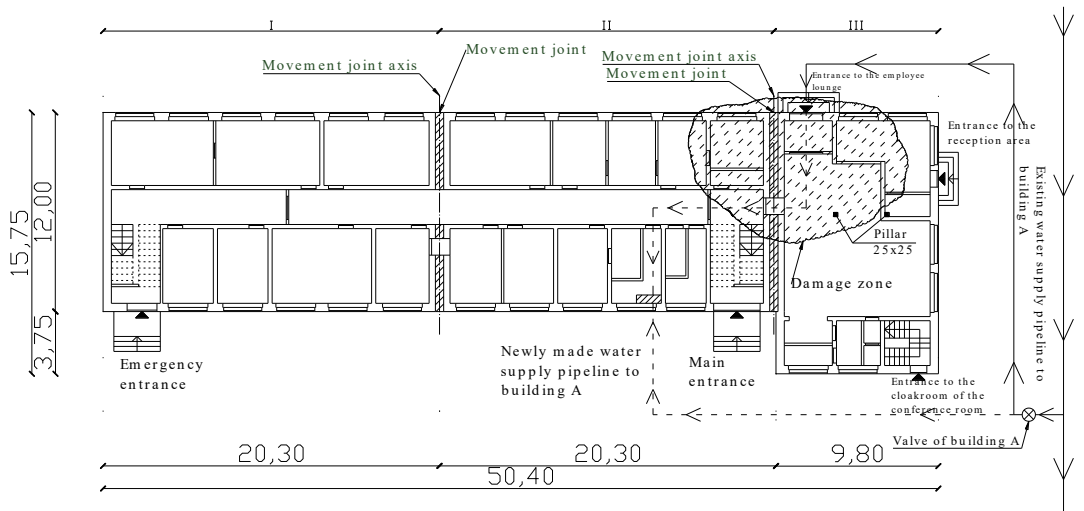

Fig. 7. Location of damage in the office building.

\section{Damage development}

In the period since August 2018, changes in the damage to the structure of the building is monitored on an ongoing basis, both in terms of their location and size.

During the initial 1.5-month period, increase in the crack apertures and cracking of the walls were observed, the increased tilting of the floors on the ground floor of the building was noticed along with the appearance of new damage. The biggest increase in the crack aperture of the ground floor walls in this period amounted to $24 \mathrm{~mm}$. In one of the walls located near the movement joints on the ground floor, a sectional, horizontal deformation was also determined (to the inside of the room - Fig. 8).

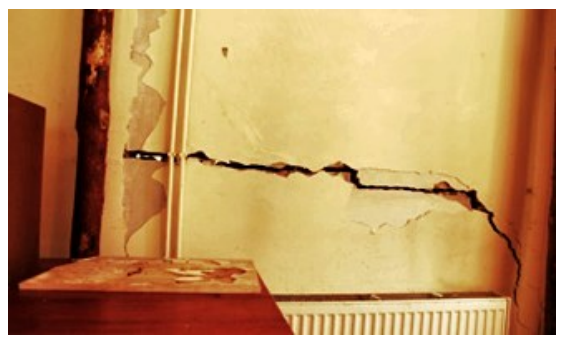

Fig. 8. Cracking of the wall located near the movement joints of the ground floor of the building with horizontal displacements of its parts.

Since mid-November 2018, a marked stabilization of the structure deformation has been observed and since the second half of December 2018 their full extinction has occurred.

\section{Determining the causes of damage to the building structure}

During the previous 50 years of operation of the building, its structure has not been reconstructed and the load characteristics did not change during that time. Considering such conditions, the sudden occurrence of damage to a part of the building could only have a causal relationship with the change of the conditions of its foundation. In the further part of the paper, the findings from tests and inspections of water supply and sanitary drainage systems, the soil and groundwater conditions of the subsoil in the area of damage to the building were presented. 


\subsection{Water supply and sanitary drainage system inspection}

The inspection of the water supply system, carried out on the day when damage to the building structure was discovered, indicated significant water losses in this system. An immediate decision was made to shut off the supply for the building from this system.

The check consisted in the CCTV inspection of the sanitary and stormwater drainage system running in the building as well as its immediate vicinity. It was determined that this system was not damaged except that the outer drainage made of stoneware pipes has a lot of ingrown roots due to many years of use, which narrows its effective cross-sections.

\subsection{Investigations of subsurface and groundwater conditions}

The soil and groundwater conditions of the subsoil in the area adjacent to the building damage zone were identified on the basis of 6 boreholes: 4 holes were made inside the office rooms on the ground floor and 2 holes were made with a truck-mounted drilling rig in the vicinity of external load-bearing walls.

\subsubsection{Investigations}

Based on the investigations conducted, two layers (layer I and II) composed of embankment soil were distinguished, while layers III and IV constitute the natural soil.

Layer I (embankment) thickness 0.3 - 0.7 m consists of medium-dense sand-gravel mix. It is a load-bearing layer, not very compressible. At the boundary of the flooring of the building ground floor and the sand-gravel voids were found in the following holes: $1-5 \mathrm{~cm}$, $2-2 \mathrm{~cm}, 5-2 \mathrm{~cm}$, while in the hole No 6 , a $2-\mathrm{cm}$ void was found at the location of the slip membrane.

Layer II (embankment) is made of brown and locally red coloured metallurgical slag of variable grain size composition on the border between loose and medium dense condition. Within layer II, voids were found in the following holes: $1-0.9 \mathrm{~m}, 2-0.2 \mathrm{~m}$ and in hole No 6 , a zone of loosening the soil was observed at a depth of $2.0-2.6 \mathrm{~m}$.

Layer III (natural soil) is developed as a gray loam in the soft state This is a poorly loadbearing and compressible layer.

Layer IVa (natural soil) is formed as red sandstone of the Grodziec Beds representing the Upper Carboniferous age, i.e. Namurian. It is a soft rock with compressive strength $\mathrm{Rc}<5 \mathrm{MPa}$.

Layer IVb (natural soil) is formed as gray-coloured clayshale of the Grodziec Beds representing the Upper Carboniferous: Namurian. It is a soft rock with compressive strength $\mathrm{Rc}<5 \mathrm{MPa}$.

Figs 9-10 illustrate the exemplary structure of the investigated subsoil. 


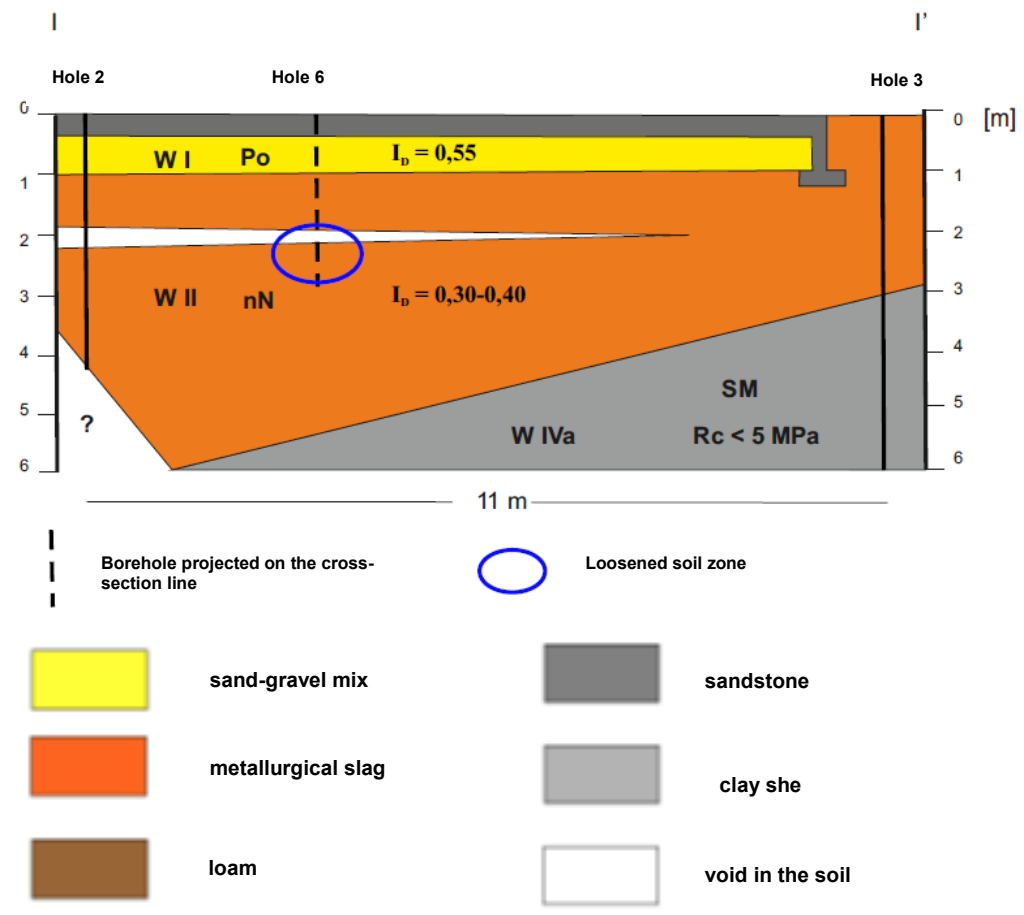

Fig. 9. Geotechnical cross-section I-I.

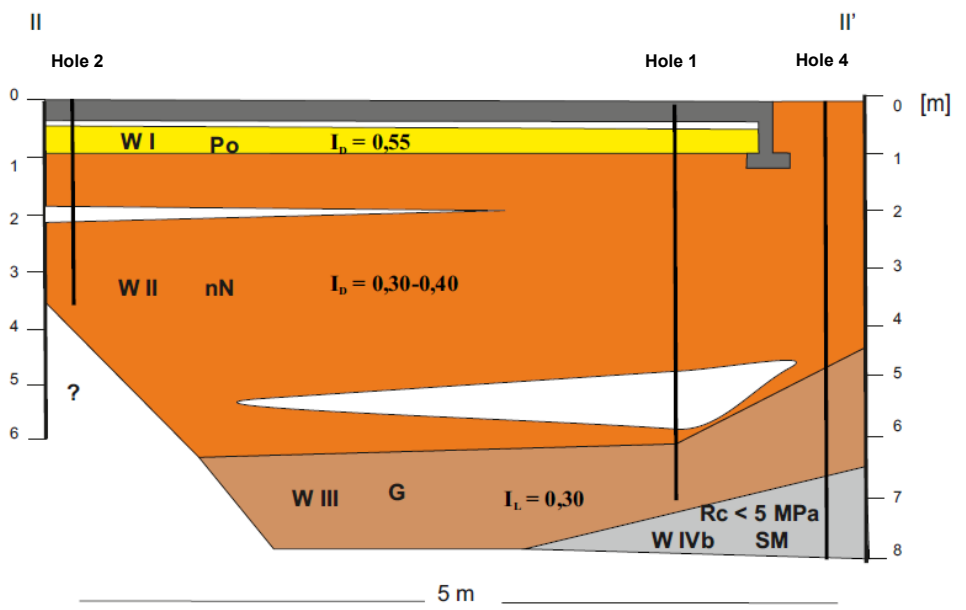

Fig. 10. Geotechnical cross-section II-II. 


\subsubsection{Subsoil assessment}

The building is constructed on a layer of metallurgical slag of the varied thickness (between $2.8 \mathrm{~m}$ and $5.0 \mathrm{~m}$ ). Currently, the slag is in the medium dense state and parts of it are in the loose state.

The occurrence of two void types in the soil was determined during drilling. These are the voids formed at the boundary between the concrete flooring and its underpin (with a height between $2 \mathrm{~cm}$ and $5 \mathrm{~cm}$ ) and intra-layer voids within layer II - metallurgical slag. The second type are soil voids occurring at various depths: in bore hole No. 1 at a depth between $4.8 \mathrm{~m}$ below flooring level (b.f.l.) and $5.7 \mathrm{~m}$ b.f.l. and in borehole No. 2 at a depth between $1.9 \mathrm{~m}$ b.f.l. and $2.1 \mathrm{~m}$ b.f.l. During the investigations, varied degree of the moisture content of the slag was observed: from moist up to wet and soft.

On the basis of the moisture content distribution analysis it was inferred that the increase in the moisture content up to wet conditions is probably caused by infiltration of atmospheric water or leaks from a damaged water supply system.

\subsubsection{Geophysical assessment of the subsoil}

In August 2018, a scientific-research unit specializing in geophysical survey carried out investigations of the subsoil (rock mass) with the use of the GPR method.

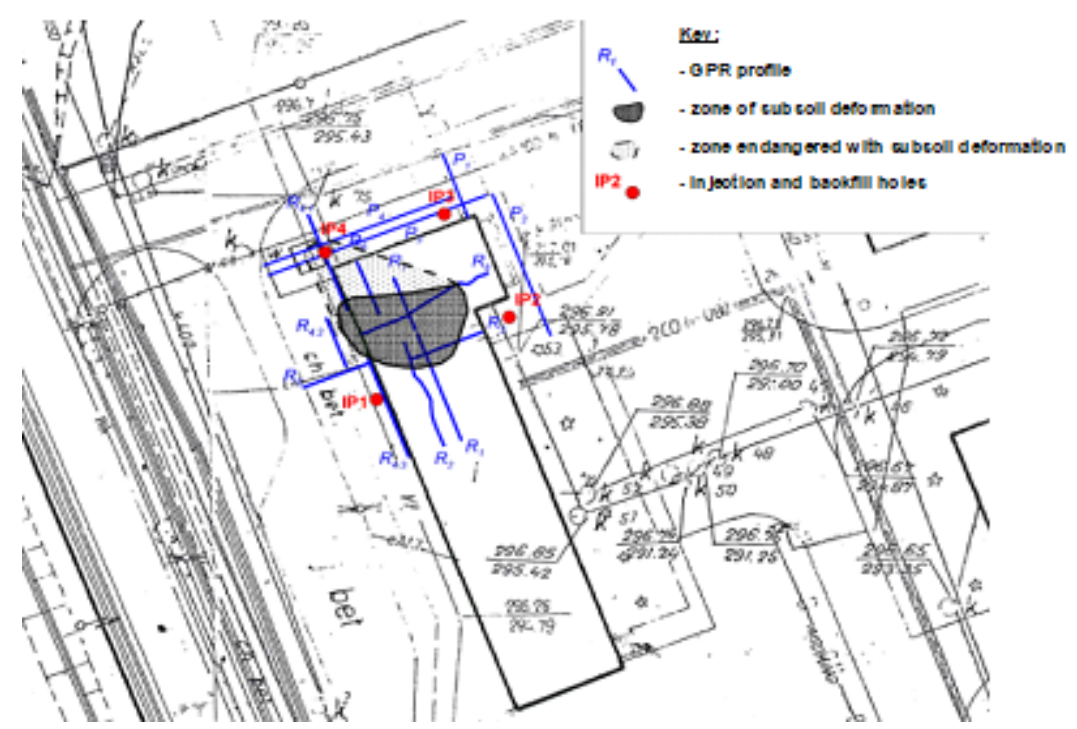

Fig. 11. Location of geophysical survey profiles.

\subsubsection{Geophysical survey results}

After processing the obtained records of the radar sections a wave, three-layered image of the subsoil structure to the depth of ca. $4 \mathrm{~m}-6 \mathrm{~m}$ (Fig. 12) emerged. These layers could be described as follows:

I) A surface layer with a thickness of ca. 1-1.2 m. Foundations of floors of office rooms are in this layer. In the area of damage to structural elements (walls, concrete flooring of the ground floor), the thickness of this layer is clearly increased by ca. $0.1-0.3 \mathrm{~m}$. 


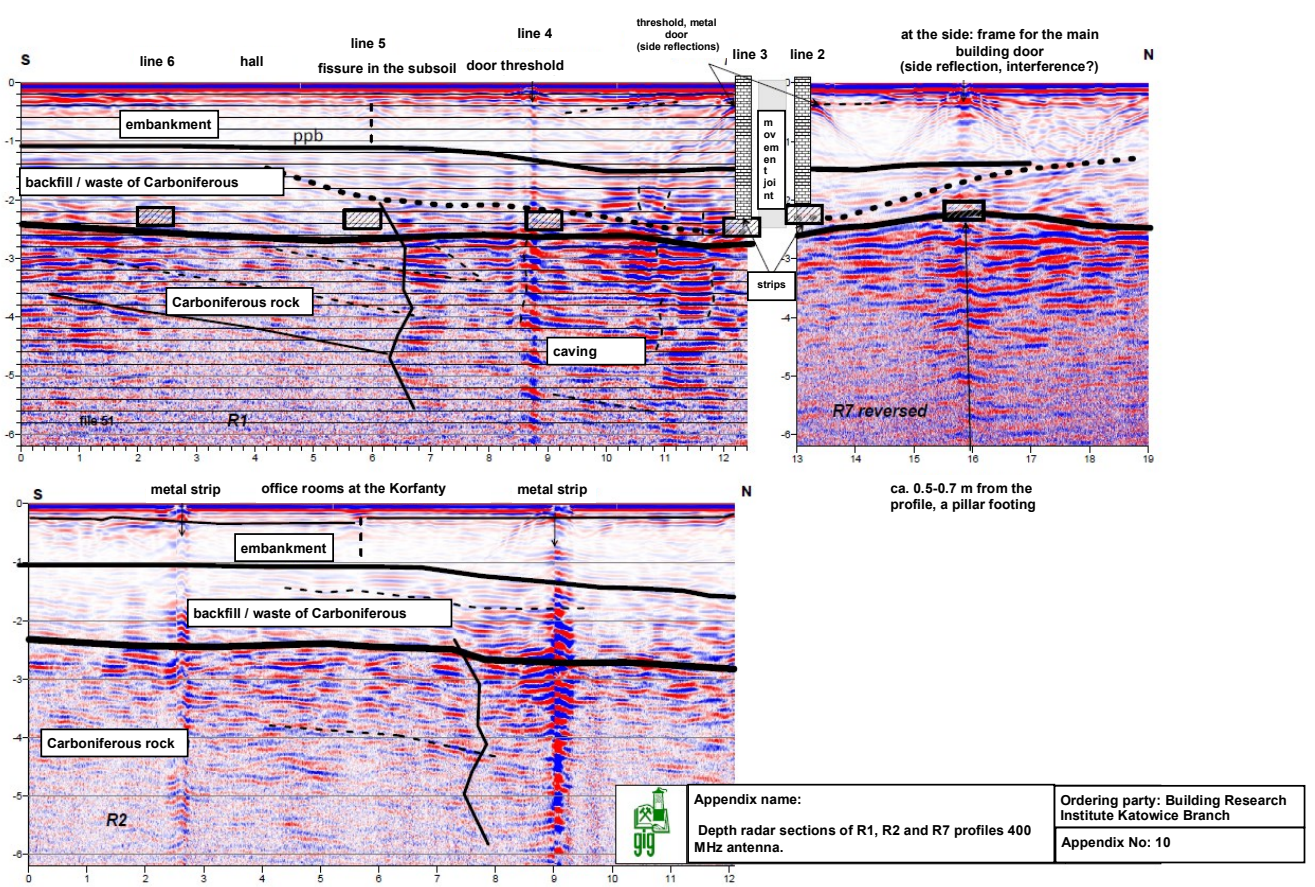

Fig. 12. Example of depth radar sections R1, R2 and R7.

II/ Layer present below layer I, within a depth interval between ca. 1.0 and ca. $2.8 \mathrm{~m}$. The average depth of occurrence of the layer roof is around $1.2 \mathrm{~m}$. It lowers distinctly in the area of damage to the building structure. This layer is built of the soil formed as a result of weathering of the Carboniferous rock (loamy and sandy rubble).

III / On the waveform images a reflexive horizon is visible that determines the location of the roof of this layer at a depth of 2.2 to $2.8 \mathrm{~m}$. This horizon most probably corresponds to the position of the roof of less weathered Carboniferous deposits (sandstone). However, considering the information from the archival geological map, it cannot be ruled out that the layer is built of the soil which has been used to cover a depression (most probably the filling material was a waste stone from hard coal production, sinter from metallurgical furnaces or a mixture of these).

On part of the images, local inclined several-kilometer-long reflexive horizons have appeared, which may point to the presence of delamination within the rock substrate or boundaries of the layers differing in their moisture content. In some places within layers II and III there are also visible disturbances in the wave image that may imply the presence of vertical or nearly vertical fissures (radar pulse damping zones, a small range horizontal signals reminiscent of diffraction hyperbolae). Such disturbances in the structure of the layers are visible in particular in the area where the deformations of the subsoil of the building occurred.

On one of the profiles (Fig. 13) at a depth of 7 to $10 \mathrm{~m}$ (i.e. in the layer that most likely is already a compact Carboniferous rock) a group of reflections with a relatively large amplitude was revealed. At this point, a mine heading is visible on the mining seam map. It is therefore plausible that the registered wave anomaly was caused by the presence in the Carboniferous subsoil of secondary mining voids created as a result of the heading collapse. 

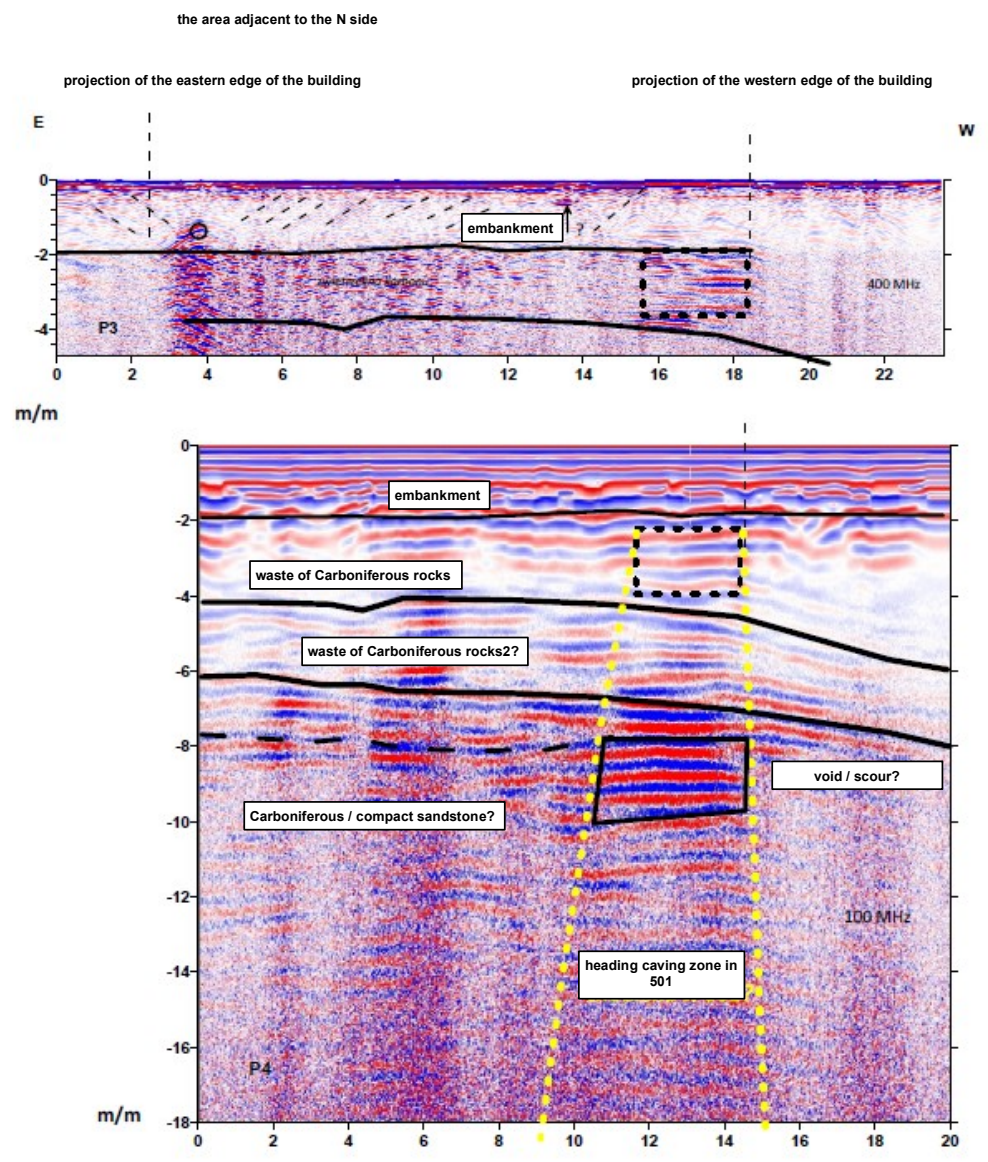

Fig. 13. Depth radar sections of $\mathrm{P} 3$ and $\mathrm{P} 4$ profiles.

On the following measurement profiles between ca. 15.5 and $18.5 \mathrm{~m}$ (the area of the north-western corner of the building) a group of horizontal reflections is visible, which may be indicative of the presence of a zone of strong loosening of the soil in this location.

\subsubsection{Interpretation of mining and geophysical data}

Analysis of mining data implies that the entire office building is located in the post-mining area (Fig. 14), where in the period from about 1885 until the end of the 1920s, a 6- to 7meter-thick seam was exploited using the roof caving method. The base of this seam occurred at a depth of ca. $23 \mathrm{~m}$. The exploitation was carried out using the roof and pillar system and resulted in alteration of the structure of the overburden layers. Because a thick bed of sandstone occurs between the coal seam and the original land surface, mining exploitation caused only localized cracking of it. 


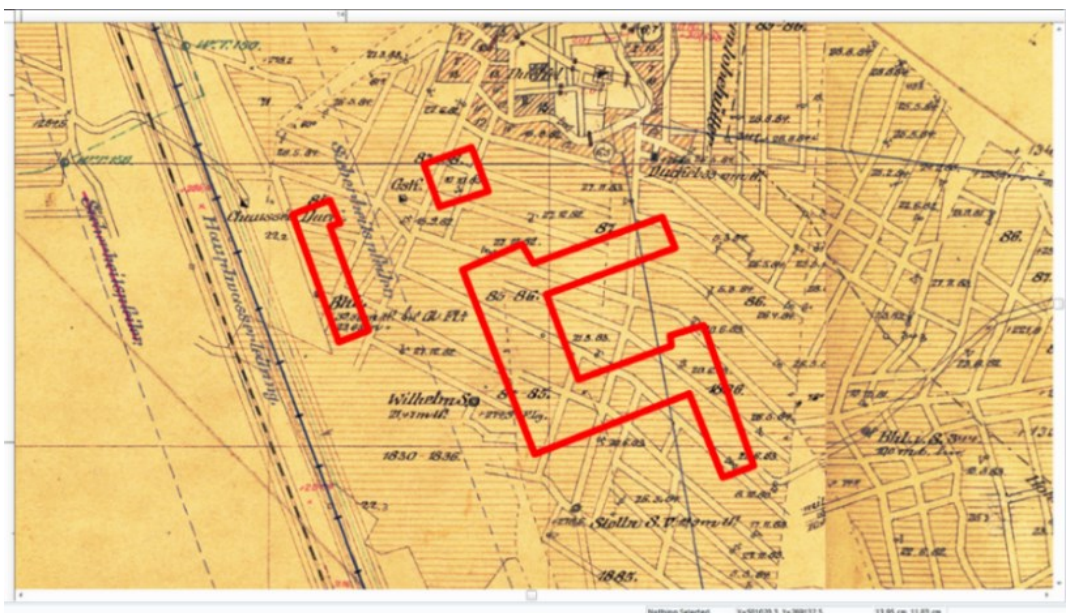

Fig. 14. Location of the building in the area of old mining exploitation.

Based on a mining map analysis it can be assumed that there were 6 or 7 mining plots in the area of the land strip covering the building plan. The plots were divided by mine headings. These headings indicate the most probable places where the continuity of the overburden layers could have been interrupted. Three of such headings are located in the area of damages in the building structure.

On the basis of the analysis of the results of geophysical surveys, it can be assumed with high probability that these headings collapsed creating primary and secondary voids at depths of around $8-10 \mathrm{~m}$. The presence of voids may be connected both with the underground exploitation of the coal seam directly under the building at a depth of 15 meters or with the opencast extraction carried out in the area of outcrop of this seam (voids in the backfilling material of the open pit). Rainwater and water from the inefficient supply pipe may enter these voids and fissures causing leaching of loose soils from the subsurface layer on which the foundation strips of the building are located.

\section{Restoration of the technical efficiency of the building}

\subsection{General issues}

The office building, being in operation since 1966, did not show any damage or irregularities before. The structural damage dates back to the first days of August to the current year and their cause is connected with a failure of the water supply pipeline located directly under the basement-free part of the building (contact of the northern segment and the central segment). Under such conditions, uncontrolled leakage of water into the subsoil could cause leaching of the loose soil from the near-surface layer, on which the foundation strips were located, which caused their increased and uneven subsidence. However, it should be emphasized that the construction of the foundations, designed in 1963, was not sufficient to withstand the influence of the mining deformation of the area corresponding to category IIa (discontinuous deformations of the land surface).

Since the damage occurred, the process of its development was observed in the first 12 16 days. Next, the damage growth process (aperture of the wall cracks, inclination of floors on the ground floor) decreased significantly, and in December 2018, the size of previous damage stabilized. 
All the renovation and repair works consisting in restoring the original technical parameters of the building should be divided into four phases:

Phase I - reconstruction of the damaged pipeline supplying the building with water,

Phase II and III - stabilization and strengthening of the subsoil,

Phase IV - reinforcements and renovation of the building structure and its finishing elements.

\subsection{Restoring stability of the subsoil}

Phase I - During the month of September 2018, the pipeline supplying the building with water was replaced and its course was situated in a new location.

Phase II - will cover drilling and backfilling work in the area from the roof of Carboniferous deposits to the floor of the coal seam. As a result of this work, voids and cracks should be filled within the Carboniferous rock massif. For this purpose, it was recommended to drill 4 boreholes 25-28 m deep, whose location is shown in Fig. 15. These holes will be used to carry out filling of the voids and cracks in the Carboniferous rock massif initially with the gravity method and next using a pressure not exceeding $0.3 \mathrm{MPa}$. The injection material will be hydraulic cements madeof fly ash, water and cement. These works will be carried out outside the building.

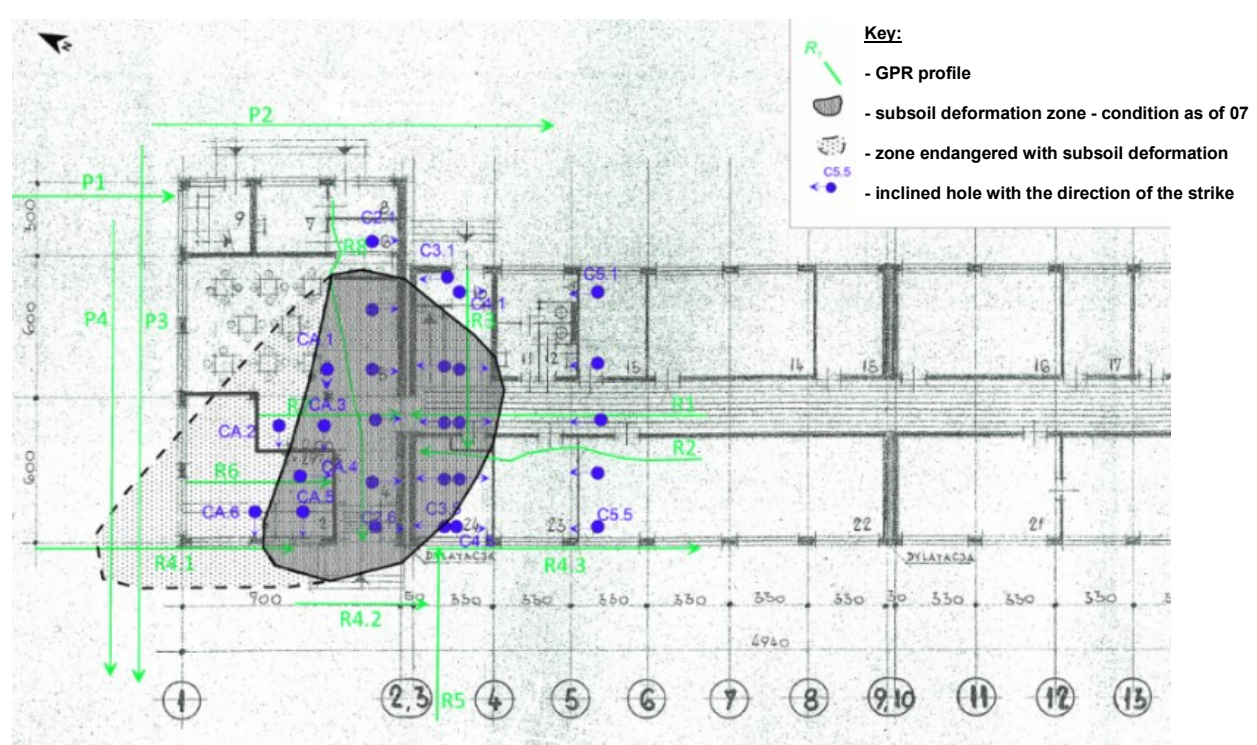

Fig. 15. Concept of location of injection holes to strengthen the subsoil under an existing building.

Phase III - will include injection and cement work in the depth zone of 2-3 m made with the use of inclined holes in the vicinity of the strips. These works will be carried out inside the building. The distance between the holes should be $2-3 \mathrm{~m}$. The holes will be drilled at a distance of ca. $1 \mathrm{~m}$ from the walls at an angle of $75^{\circ}$ (to the vertical) in the direction of the strips. The injection would be carried out using the pressure method, and the injected medium will be a mixture of cement and water. The length of the holes should be $3.5 \mathrm{~m}$. The execution of 27 injection holes is planned. The purpose of this work is to consolidate the soil in the subsoil near the strip foundations in the damaged part of the building. 
Phase IV - construction works

Restoration of the technical efficiency of the structure of the cracked fragments of the load-bearing walls with an aperture of over $5 \mathrm{~mm}$ will be based on partial replacement (areas with horizontal deformation) and their re-walling. The purpose of this work is to reconstruct the original rigid system of the structure.

Walls with smaller damage (hair cracks and cracks with an aperture $<5 \mathrm{~mm}$ ) will be repaired using pressure injection.

After repairing the damaged walls, replacement will be done of the damaged / deformed window and door joinery.

The deformed concrete flooring in ground floor rooms will be replaced after disassembly of sections of the damaged flooring.

Lastly, it was recommended to replace / restore the damaged fragments of the thermal insulation of external walls along with the unification of the painting of the walls of the extreme northern segment and the central segment (the eastern façade).

\section{Summary}

Even in buildings that have been until now operated properly and without defects (50 years), their structure may be damaged due to unforeseen random events (such as the failure of the water supply system). Damage sizes can be additionally multiplied following to not very well recognized geotechnical conditions (e.g. those related to the location of facilities in the postmining areas). The probable cause of the damage was the faulty water supply system and the possible activation of the rock mass due to the erosion processes of the heading lining. After a marked stabilization of the land surface depressions and the process of damage enlargement, the process of soil subsoil treatment and repair of damaged building elements was commenced.

\section{References}

1. Design project: Preliminary design and permit design of the administrative building (Gliwice Office of Industrial Construction Design, 1963) [in Polish]

2. Report: Ground expertise in the area of deformation of the local building located in the post-mining area (Central Mining Institute, Katowice, 2018) [in Polish]

3. A. Kotyrba, Assessment of threats from shallow mining voids for the planned overhaul of the gas pipeline based on geophysical surveys and analysis of geological and mining conditions (Central Mining Institute, 1997) [in Polish]

4. Instruction No 364/2007. Technical Requirements for Buildings and Structures Constructed in Mining Areas (Instrytut Techniki Budowlanej, Warszawa, 2007) [in Polish]

5. Instruction No 416/2006. Designing Buildings in Mining Areas (Instrytut Techniki Budowlanej, Warszawa, 2006) [in Polish] 